\title{
Volumetric breast density affects performance of digital screening mammography
}

\author{
Johanna O. P. Wanders ${ }^{1} \cdot$ Katharina Holland $^{2} \cdot$ Wouter B. Veldhuis $^{3}$. \\ Ritse M. Mann ${ }^{2}$ Ruud M. Pijnappel ${ }^{3,4} \cdot$ Petra H. M. Peeters $^{1,5}$. \\ Carla H. van Gils ${ }^{1}$. Nico Karssemeijer ${ }^{2}$
}

Received: 12 December 2016/ Accepted: 16 December 2016/Published online: 23 December 2016

(c) The Author(s) 2016. This article is published with open access at Springerlink.com

\begin{abstract}
Purpose To determine to what extent automatically measured volumetric mammographic density influences screening performance when using digital mammography (DM).

Methods We collected a consecutive series of 111,898 DM examinations (2003-2011) from one screening unit of the Dutch biennial screening program (age 50-75 years). Volumetric mammographic density was automatically assessed using Volpara. We determined screening performance measures for four density categories comparable to the American College of Radiology (ACR) breast density categories.

Results Of all the examinations, $21.6 \%$ were categorized as density category 1 ('almost entirely fatty') and 41.5, 28.9, and $8.0 \%$ as category 2-4 ('extremely dense'), respectively. We identified 667 screen-detected and 234 interval cancers. Interval cancer rates were 0.7, 1.9, 2.9,
\end{abstract}

Carla H. van Gils and Nico Karssemeijer share last authorship.

Carla H. van Gils

C.vanGils@umcutrecht.nl

1 Julius Center for Health Sciences and Primary Care, University Medical Center Utrecht, P.O. Box 85500, 3508 GA Utrecht, The Netherlands

2 Department of Radiology and Nuclear Medicine, Radboud University Medical Center, Geert Grooteplein 10, 6525 GA Nijmegen, The Netherlands

3 Department of Radiology, University Medical Center Utrecht, P.O. Box 85500, 3508 GA Utrecht, The Netherlands

4 Dutch Reference Centre for Screening, Postbus 6873, 6503 GJ Nijmegen, The Netherlands

5 MRC-PHE Centre for Environment and Health, Department of Epidemiology and Biostatistics, School of Public Health, Imperial College, London, St. Mary's Campus, Norfolk Place W2 1PG, London, UK and $4.4 \%$ and false positive rates were $11.2,15.1,18.2$, and $23.8 \%$ for categories 1-4, respectively (both $p$ trend $<0.001)$. The screening sensitivity, calculated as the proportion of screen-detected among the total of screendetected and interval tumors, was lower in higher density categories: $85.7,77.6,69.5$, and $61.0 \%$ for categories $1-4$, respectively ( $p$-trend $<0.001)$.

Conclusions Volumetric mammographic density, automatically measured on digital mammograms, impacts screening performance measures along the same patterns as established with ACR breast density categories. Since measuring breast density fully automatically has much higher reproducibility than visual assessment, this automatic method could help with implementing density-based supplemental screening.

Keywords Mammographic density - Breast cancer · Cancer screening $\cdot$ Mammography $\cdot$ Breast

$\begin{array}{ll}\text { Abbreviations } \\ \text { DM } & \text { Digital mammography } \\ \text { ACR } & \text { American College of Radiology } \\ \text { USA } & \text { United States of America } \\ \text { BI-RADS } & \text { Breast imaging-reporting and data system } \\ \text { MRI } & \text { Magnetic resonance imaging } \\ \text { CC } & \text { Craniocaudal } \\ \text { MLO } & \text { Mediolateral oblique } \\ \text { ICD-O } & \text { International classification of diseases for } \\ & \text { oncology } \\ \text { PDV } & \text { Percentage dense volume } \\ \text { VDG } & \text { Volpara density grade } \\ \text { GEE } & \text { Generalized estimating equations } \\ \text { DR } & \text { Direct radiography } \\ \text { DMIST } & \text { Digital mammographic imaging screening trial } \\ \text { BCSC } & \text { Breast cancer surveillance consortium }\end{array}$


FSM Film-screen mammography

PPV Positive predictive value

CI Confidence interval

DCIS Ductal carcinoma in situ

\section{Introduction}

Breast density increases breast cancer risk [1, 2]. In addition, sensitivity of screening mammography is lower for women with dense breasts, caused by the masking effect of dense (fibroglandular) breast tissue [3, 4]. This has led to breast density legislation in 28 states of the United States of America (USA) until now, and has fueled ongoing discussions on the need for supplemental screening for women with dense breasts worldwide [5].

One hoped that screening performance in women with dense breasts would improve when film-screen mammography (FSM) was replaced by digital mammography (DM). Unfortunately, screening sensitivity was still worse in women with dense compared to nondense breasts when DM was used [6-8]. Most large studies looking into the effect of breast density on screening performance used the breast imaging reporting and data system (BI-RADS) for breast density assessment, which is assessed by radiologists. However, this method has a moderate inter-observer agreement [9-12].

With the advent of digital mammography, several fully automatic volumetric density assessment methods have been developed. Volpara is one of these methods, and has shown correlation with BI-RADS density categories and MRI breast density measurements [13-16].

The effect of automatically measured volumetric breast density on screening sensitivity has only been studied once [17]. However, information about the effect of automatically measured volumetric breast density on other screening performance measures like recall rates, false positive rates, and positive predictive values (PPV) was not given in this study. Therefore, the aim of this study was to examine to what extent automatically measured volumetric mammographic density affected screening sensitivity and other screening performance measures in a large Dutch population-based screening program cohort containing a consecutive series of digital screening mammograms and complete information about interval cancers.

\section{Materials and methods}

\section{Study population}

Data were acquired from a breast cancer screening unit (Preventicon screening unit 19, Utrecht, the Netherlands) of the Foundation of Population Screening Mid-West, one of the five screening regions of the Dutch breast cancer screening program. Women participating in this biennial screening program are aged 50-75. The program involves mammography only, and all mammograms are read by two certified screening radiologists. In the Dutch screening program, previous screening mammograms are most of the time available for comparison in case of subsequent screens.

In 2003, DM was introduced at the Preventicon screening unit [18-20]. Analog mammography systems were gradually replaced by digital ones. In July 2007, almost all mammograms at this screening unit were digital [19].

By participating in the Dutch screening program, women consent to their data being used for evaluation and improvement of the screening, unless they have indicated otherwise.

\section{Data collection}

We prospectively collected all unprocessed DM examinations that were taken at the Preventicon screening unit between 2003 and 2011, with exception of a 4-month period in 2009 when only processed data were archived. All mammograms were acquired using Lorad Selenia DM systems (Hologic, Danbury, Conn.). The first screening examination of a woman in the screening program always included the two standard views, craniocaudal (CC) and mediolateral oblique (MLO). At subsequent screening examinations, MLO was the routinely acquired view and $\mathrm{CC}$ was acquired in $57 \%$ of the cases by indication (e.g., high breast density, visible abnormality) during the study period. Recall and breast cancer detection information was obtained from the screening registration system. Interval cancers were identified through linkage with the Netherlands Cancer Registry.

Examinations were excluded, when information about recall or final outcome was missing. In addition, examinations for which breast density could not be determined, and interval cancers diagnosed more than 24 months after the last screening mammogram were excluded for analysis.

Tumor information such as maximum diameter, nodal status, and ICD-O codes were obtained from the screening registration system. Nodes were classified negative when the sentinel lymph node, or the dissection specimen in case no sentinel lymph node procedure was performed, contained no or only isolated tumor cells. Nodes were considered positive if they contained micrometastases $(0.2-2 \mathrm{~mm})$ or metastases larger than $2 \mathrm{~mm}$.

\section{Volumetric mammographic density assessment}

Percentage dense volume (PDV) was automatically assessed from unprocessed mammograms of the left and right 
breasts, and MLO and CC views using the commercially available Volpara Density software (version 1.5.0, Volpara Solutions, Wellington, New Zealand) [21].

The average PDV per screening examination was determined using the available views of both breasts. Volpara density grades (VDGs) were constructed based on this average PDV (VDG1: $0 \% \leq \mathrm{VBD}<4.5 \%$, VDG2: $4.5 \% \leq \mathrm{VBD}<7.5 \%$, VDG3: $7.5 \% \leq \mathrm{VBD}<15.5 \%$, VDG4: VBD $\geq 15.5 \%$ ). The VDGs are designed to mimic the American College of Radiology (ACR) BI-RADS breast density categories (4th edition).

\section{Statistical analysis}

Examinations were grouped according to VDGs. Within these groups, we determined the following screening performance measures with accompanying 95\% confidence intervals (CI) using generalized estimating equations (GEE) to account for correlation between examinations of the same woman using the 'independence' correlation structure: recall rate, false positive rate, screen-detected breast cancer rate, interval breast cancer rate, total breast cancer rate (all rates are per 1000 screening examinations), sensitivity and specificity of the screening, and positive predictive value (PPV). For the screening sensitivity, we calculated Wilson's 95\% confidence intervals (see Table 1 for screening performance definitions). For comparison with American screening programs, we also determined interval cancer rates for the first year after a negative screening mammogram, since the screening interval in the USA is normally 1 year.

We performed several sensitivity analyses: (1) taking only invasive tumors into account (i.e., excluding the examinations leading to a true positive or false negative diagnosis of in situ carcinoma); (2) taking only subsequent screening rounds into account, since performance measures are expected to be different between first and subsequent rounds (in case of subsequent rounds, the prior mammogram could be analog or digital); (3) using VDGs based on the mean PDV of only the MLO views instead of using all available views.

We tested for linear trends across the four density categories for screening performance measures, the percentage of in situ cancers, and positive lymph nodes with a Chi square linear trend test. In addition, we examined whether tumors diagnosed in dense breasts were larger than in nondense breasts, using the Jonckheere-Terpstra test, as we expected tumor size not to be normally distributed. All statistical tests were two-sided. Statistical analyses were performed in IBM SPSS statistics, version 21 and in R, version 3.2.2 using the "geese" function from the "geepack" package.

\section{Results}

In total, 113,956 screening examinations were available. We excluded 50 examinations of which the screening outcome was unknown, 47 interval cancers which were diagnosed more than 24 months after the last screening examination, and 1961 examinations for which VDG could not be assessed. This resulted in 111,898 examinations belonging to 53,239 women with a median age of 58 years (IQR: 53-64 years). Among the examinations, $21.6 \%$ were categorized as density category 1 ('almost entirely fatty'), and $41.5,28.9$, and $8.0 \%$ as category $2-4$ ('extremely

Table 1 Definitions of screening performance measures

\begin{tabular}{|c|c|}
\hline FN (Interval breast cancer) & $\begin{array}{l}\text { Breast cancers diagnosed within } 24 \text { months after a screening examination that did not lead to recall (negative } \\
\text { mammogram), and before the next scheduled screening examination }\end{array}$ \\
\hline $\begin{array}{l}\text { TP (Screen-detected breast } \\
\text { cancer) }\end{array}$ & Breast cancers diagnosed after a recalled screening examination (positive mammogram) \\
\hline FP & $\begin{array}{l}\text { Screening examinations that led to a recall (positive mammogram), but not to a breast cancer diagnosis within } \\
24 \text { months after the examination, or before the next scheduled screening examination }\end{array}$ \\
\hline $\mathrm{TN}$ & $\begin{array}{l}\text { Screening examinations that did not lead to recall (negative mammogram) and no breast cancer was diagnosed } \\
\text { within } 24 \text { months after the examination, or before the next scheduled screening examination }\end{array}$ \\
\hline Sensitivity of screening & $\begin{array}{l}\text { The number of screen-detected breast cancers divided by the total number of screen-detected plus interval breast } \\
\text { cancers }((\mathrm{TP} /(\mathrm{TP}+\mathrm{FN}))\end{array}$ \\
\hline Specificity of screening & $\begin{array}{l}\text { Number of screening examinations that did not lead to recall (negative mammogram) and no breast cancer } \\
\text { diagnosis within } 24 \text { months, or before the next scheduled screening examination divided by the total number of } \\
\text { examinations without breast cancer diagnosis within } 24 \text { months, or before the next scheduled screening } \\
\text { examination }((\mathrm{TN} / \mathrm{TN}+\mathrm{FP}))\end{array}$ \\
\hline PPV & $\begin{array}{l}\text { The number of screen-detected breast cancers divided by the total number of examinations that led to recall ((TP/ } \\
(\mathrm{TP}+\mathrm{FP}))\end{array}$ \\
\hline
\end{tabular}

$F N$ false negative, $T P$ true positive, $F P$ false positive, $T N$ true negative, $P P V$ positive predictive value 
dense'), respectively (Table 2). In total, 667 screen-detected breast cancers were identified based on a mammogram taken before January 1, 2012, and 234 interval cancers were identified within 24 months after a mammogram taken before January 1, 2012, of which 79.5 and $97.9 \%$, respectively, were invasive breast cancers (Tables 2, 4).

\section{Screening performance across volumetric density categories}

Table 3 shows that total and interval breast cancer rates, recall rates, and false positive rates were higher in higher breast density categories compared to lower density categories, all with a significant linear trend ( $p$-trend $<0.001)$. Screen-detected breast cancer rates were found to be lowest in the lowest breast density category (4.0 per 1000 examinations (\%o)) and more comparable across the three highest breast density categories: 6.4, 6.6, and 6.8\%o, respectively ( $p$-trend $<0.001$ ). The screening sensitivity was significantly lower $(p$-trend $<0.001)$ in higher breast density categories: $85.7,77.6,69.5$, and $61.0 \%$ in VDG categories 1-4, respectively. No significant linear trend was found for PPV ( $p$-trend $=0.12$ ) (Table 3).

Overall trends for interval cancer rates, recall rates and false positive rates, screening sensitivity and specificity were similar when either invasive cancers alone or both invasive cancer and in situ cancers were taken into account.
However, when restricting the analyses to invasive cancers only, the screening sensitivity in VDG4 decreased most notably compared to the screening sensitivity when both in situ and invasive breast cancers were taken into account. When only subsequent screening rounds were taken into account, the overall trends were again similar to the analyses based on both first and subsequent screening examinations (Table 3 ). The results of the sensitivity analysis, where PDV was based on MLO views only, did not differ from those based on all available views (data not shown).

In VDG category $1,25 \%$ of the interval breast cancers were diagnosed in the first year after screening examination; in VDG categories 2 and 3, this was $41 \%$ and in VDG category $467 \%$. This resulted in interval cancer rates in the first year after a screening examination of $0.2,0.8,1.2$, and $2.9 \%$ ( $p$-trend $<0.001$ ) in VDG categories $1,2,3$, and 4 , respectively.

\section{Tumor characteristics across volumetric density categories}

Of all tumors, $74.0 \%$ were screen-detected and $26.0 \%$ were interval cancers. $15.7 \%$ of all tumors were in situ and $84.3 \%$ were invasive tumors. $89.4 \%$ of the in situ tumors showed microcalcifications on the last screening mammogram. For screen-detected tumors, the highest proportion of in situ tumors was found in the highest density category (in VDG4, $32.8 \%$ of the screen-detected tumors were in situ

Table 2 Number of mammography examinations in total and within Volpara Density Grade (VDG) categories (based on the available views)

\begin{tabular}{|c|c|c|c|c|c|}
\hline & Total & VDG 1 & VDG 2 & VDG 3 & VDG 4 \\
\hline \multicolumn{6}{|l|}{ Total } \\
\hline Screening examinations $[N(\%)]$ & $111,898(100 \%)$ & $24,210(21.6 \%)$ & $46,426(41.5 \%)$ & $32,330(28.9 \%)$ & $8932(8.0 \%)$ \\
\hline Screen-detected cancers $(N)$ & 667 & 96 & 298 & 212 & 61 \\
\hline Interval cancers $(N)$ & 234 & 16 & 86 & 93 & 39 \\
\hline False positives $(N)$ & 1774 & 271 & 700 & 590 & 213 \\
\hline True negatives $(N)$ & 109,223 & 23,827 & 45,342 & 31,435 & 8619 \\
\hline \multicolumn{6}{|c|}{ Only invasive tumors taken into account } \\
\hline Screening examinations $[N(\%)]$ & $111,754(100 \%)$ & $24,188(21.6 \%)$ & $46,375(41.5 \%)$ & $32,279(28.9 \%)$ & $8912(8.0 \%)$ \\
\hline Screen-detected cancers $(N)$ & 529 & 75 & 250 & 163 & 41 \\
\hline Interval cancers $(N)$ & 228 & 15 & 83 & 91 & 39 \\
\hline False positives $(N)$ & 1774 & 271 & 700 & 590 & 213 \\
\hline True negatives $(N)$ & 109,223 & 23,827 & 45,342 & 31,435 & 8619 \\
\hline \multicolumn{6}{|l|}{ Only subsequent screening rounds } \\
\hline Screening examinations $[N(\%)]$ & $94,665(100 \%)$ & $22,146(23.4 \%)$ & $40,664(43.0 \%)$ & $25,777(27.2 \%)$ & $6078(6.4 \%)$ \\
\hline Screen-detected cancers $(N)$ & 521 & 86 & 249 & 152 & 34 \\
\hline Interval cancers $(N)$ & 203 & 16 & 81 & 80 & 26 \\
\hline False positives $(N)$ & 1170 & 214 & 491 & 366 & 99 \\
\hline True negatives $(N)$ & 92,771 & 21,830 & 39,843 & 25,179 & 5919 \\
\hline
\end{tabular}


Table 3 Screening performance measures in total and within volpara density grade (VDG) categories (based on the available views)

\begin{tabular}{|c|c|c|c|c|c|c|}
\hline & \multicolumn{5}{|c|}{$\begin{array}{l}\text { Screening performance measures }(95 \% \mathrm{CI}) \text { for total population and within VDG breast density } \\
\text { categories }\end{array}$} & \multirow[t]{2}{*}{$p$ trend } \\
\hline & Total & VDG 1 & VDG 2 & VDG 3 & VDG 4 & \\
\hline \multicolumn{7}{|l|}{ Total } \\
\hline Recall/1000 & $21.8(20.9 ; 22.7)$ & $15.2(13.7 ; 16.8)$ & $21.7(20.2 ; 22.9)$ & $24.8(23.1 ; 26.6)$ & $30.7(27.2 ; 34.5)$ & $<0.001$ \\
\hline FP/1000 & $15.9(15.1 ; 16.6)$ & $11.2(9.9 ; 12.6)$ & $15.1(14.0 ; 16.2)$ & $18.2(16.8 ; 19.8)$ & $23.8(20.8 ; 27.3)$ & $<0.001$ \\
\hline Screen-detected cancer $/ 1000$ & $6.0(5.5 ; 6.4)$ & $4.0(3.2 ; 4.8)$ & $6.4(5.7 ; 7.2)$ & $6.6(5.7 ; 7.5)$ & $6.8(5.3 ; 8.8)$ & $<0.001$ \\
\hline Interval cancer/1000 & $2.1(1.9 ; 2.4)$ & $0.7(0.4 ; 1.1)$ & $1.9(1.5 ; 2.3)$ & $2.9(2.3 ; 3.5)$ & $4.4(3.2 ; 6.0)$ & $<0.001$ \\
\hline $\mathrm{BC} / 1000$ & $8.1(7.6 ; 8.7)$ & $4.6(3.8 ; 5.6)$ & $8.3(7.5 ; 9.1)$ & $9.4(8.4 ; 10.5)$ & $11.2(9.2 ; 13.6)$ & $<0.001$ \\
\hline Sensitivity of screening $(\%)$ & $74.0(71.1 ; 76.7)$ & $85.7(78.1 ; 91.0)$ & $77.6(73.2 ; 81.5)$ & $69.5(64.1 ; 74.4)$ & $61.0(51.2 ; 70.0)$ & $<0.001$ \\
\hline Specificity $(\%)$ & $98.4(98.3 ; 98.5)$ & $98.9(98.7 ; 99.0)$ & $98.5(98.4 ; 98.6)$ & $98.2(98.0 ; 98.3)$ & $97.6(97.2 ; 97.9)$ & $<0.001$ \\
\hline PPV (\%) & $27.3(25.6 ; 29.1)$ & $26.2(21.9 ; 30.9)$ & $29.9(27.1 ; 32.8)$ & $26.4(23.5 ; 29.6)$ & $22.3(17.7 ; 27.6)$ & 0.12 \\
\hline \multicolumn{7}{|c|}{ Only invasive tumors taken into account } \\
\hline Recall/1000 & $20.6(19.8 ; 21.4)$ & $14.3(12.9 ; 15.9)$ & $20.5(19.2 ; 21.8)$ & $23.3(21.7 ; 25.1)$ & $28.5(25.2 ; 32.3)$ & $<0.001$ \\
\hline FP/1000 & $15.9(15.1 ; 16.6)$ & $11.2(9.9 ; 12.6)$ & $15.1(14.0 ; 16.3)$ & $18.3(16.9 ; 19.8)$ & $23.9(20.9 ; 27.4)$ & $<0.001$ \\
\hline Screen-detected cancer $/ 1000$ & $4.7(4.3 ; 5.1)$ & $3.1(2.5 ; 3.9)$ & $5.4(4.8 ; 6.1)$ & $5.0(4.3 ; 5.9)$ & $4.6(3.4 ; 6.2)$ & 0.02 \\
\hline Interval cancer/1000 & $2.1(1.9 ; 2.4)$ & $0.6(0.4 ; 1.0)$ & $1.8(1.4 ; 2.2)$ & $2.8(2.3 ; 3.5)$ & $4.4(3.2 ; 6.0)$ & $<0.001$ \\
\hline $\mathrm{BC} / 1000$ & $6.9(6.4 ; 7.3)$ & $3.7(3.0 ; 4.6)$ & $7.2(6.5 ; 8.0)$ & $7.9(7.0 ; 8.9)$ & $9.0(7.2 ; 11.1)$ & $<0.001$ \\
\hline Sensitivity of screening $(\%)$ & $69.1(66.5 ; 73.0)$ & $83.3(74.3 ; 89.6)$ & $74.4(70.2 ; 79.4)$ & $62.9(58.1 ; 69.8)$ & $50.6(40.5 ; 61.9)$ & $<0.001$ \\
\hline Specificity $(\%)$ & $98.4(98.3 ; 98.5)$ & $98.9(98.7 ; 99.0)$ & $98.5(98.4 ; 98.6)$ & $98.2(98.0 ; 98.3)$ & $97.6(97.2 ; 97.9)$ & $<0.001$ \\
\hline PPV $(\%)$ & $23.0(21.3 ; 24.7)$ & $21.7(17.6 ; 26.3)$ & $26.3(23.6 ; 29.2)$ & $21.6(18.9 ; 24.7)$ & $16.1(12.1 ; 21.2)$ & 0.02 \\
\hline \multicolumn{7}{|c|}{ Only subsequent screening rounds taken into account } \\
\hline Recall/1000 & $17.9(17.0 ; 18.7)$ & $13.5(12.1 ; 15.2)$ & $18.2(16.9 ; 19.5)$ & $20.1(18.4 ; 21.9)$ & $21.9(18.5 ; 25.9)$ & $<0.001$ \\
\hline FP/1000 & $12.4(11.7 ; 13.1)$ & $9.7(8.4 ; 11.0)$ & $12.1(11.1 ; 13.2)$ & $14.2(12.8 ; 15.7)$ & $16.3(13.3 ; 19.9)$ & $<0.001$ \\
\hline Screen-detected cancer $/ 1000$ & $5.5(5.0 ; 6.0)$ & $3.9(3.1 ; 4.8)$ & $6.1(5.4 ; 6.9)$ & $5.9(5.0 ; 6.9)$ & $5.6(4.0 ; 7.8)$ & 0.02 \\
\hline Interval cancer/1000 & $2.2(1.9 ; 2.5)$ & $0.7(0.4 ; 1.2)$ & $2.0(1.6 ; 2.5)$ & $3.1(2.5 ; 3.9)$ & $4.3(2.9 ; 6.3)$ & $<0.001$ \\
\hline $\mathrm{BC} / 1000$ & $7.7(7.2 ; 8.3)$ & $4.6(3.8 ; 5.6)$ & $8.1(7.3 ; 9.0)$ & $9.0(7.9 ; 10.2)$ & $9.9(7.7 ; 12.7)$ & $<0.001$ \\
\hline Sensitivity of screening (\%) & $71.3(68.6 ; 75.1)$ & $84.3(76.0 ; 90.1)$ & $74.8(70.1 ; 79.8)$ & $64.4(59.2 ; 71.3)$ & $56.7(44.1 ; 68.4)$ & $<0.001$ \\
\hline Specificity $(\%)$ & $98.8(98.7 ; 98.8)$ & $99.0(98.9 ; 99.2)$ & $98.8(98.7 ; 98.9)$ & $98.6(98.4 ; 98.7)$ & $98.4(98.0 ; 98.7)$ & $<0.001$ \\
\hline PPV (\%) & $30.8(28.6 ; 33.0)$ & $28.7(23.8 ; 34.0)$ & $33.6(30.3 ; 37.1)$ & $29.3(25.6 ; 33.4)$ & $25.6(18.8 ; 33.7)$ & 0.35 \\
\hline
\end{tabular}

$F P$ false positive examinations, $B C$ breast cancers, $P P V$ positive predictive value. $B C / 1000=($ Screen-detected cancers $/ 1000)+($ Interval cancers/1000), Sensitivity of screening $=$ screen-detected cancers/(screen-detected cancers + interval cancers), Specificity $=$ true negative examinations/(true negative examinations + false positive examinations), PPV $=$ screen-detected cancers/(screen-detected cancers + false positive examinations)

tumors) and the lowest proportion in density category 2 (in VDG2, $15.8 \%$ of the screen-detected tumors were in situ tumors). A significant linear trend was observed for the proportion of invasive tumors over breast density categories among screen-detected tumors ( $p$-trend $=0.03$ ).

About $80 \%$ of the screen-detected and slightly over $50 \%$ of the interval invasive breast cancers were smaller than $20 \mathrm{~mm}$ (pT1 status) at diagnosis. No linear trend was found for screen-detected tumor size across the four density categories $\left(p\right.$-trend $\left.{ }_{\mathrm{SD}}=0.10\right)$ (Table 4$)$. Lymph nodes were positive in $29.3 \%$ of the screen-detected cancers and $36.8 \%$ of the interval cancers. For lymph node status, no linear trend was found across the four breast density categories for screen-detected breast cancers $\left(p\right.$-trend SD $\left._{\mathrm{S}}=0.08\right)$ (Table 4).

\section{Discussion}

We found that the sensitivity of a DM screening program was significantly lower in women with high volumetric breast density than in women with low volumetric breast density (61.0 and $85.7 \%$, respectively, $(p$-trend $<0.001)$ ). This is despite the higher recall rates in women with high compared to low breast density (30.7 and $15.2 \%$, respectively) ( $p$-trend $<0.001$ ).

A study of Destounis et al., which was recently published, also studied the screening sensitivity in four automatically determined volumetric breast density categories. They found screening sensitivities of 95, 89, 83, and $65 \%$ in density categories $1-4$, respectively. Additionally, they determined the mammographic screening sensitivity across 
Table 4 Tumor characteristics in total and within Volpara Density Grade (VDG) categories (based on the available views)

\begin{tabular}{|c|c|c|c|c|c|c|c|}
\hline & & Total & VDG 1 & VDG 2 & VDG 3 & VDG 4 & $p$ trend \\
\hline \multicolumn{8}{|l|}{ Proportion invasive tumors ${ }^{\mathrm{a}}$} \\
\hline Total $(N=898)$ & Invasive $[N(\%)]$ & $757(84.3 \%)$ & $90(80.4 \%)$ & $333(87.2 \%)$ & $254(83.6 \%)$ & $80(80.0 \%)$ & 0.49 \\
\hline Screen-detected cancer $(N=665)$ & Invasive $[N(\%)]$ & $529(79.5 \%)$ & $75(78.1 \%)$ & $250(84.2 \%)$ & $163(77.3 \%)$ & $41(67.2 \%)$ & 0.03 \\
\hline Interval cancer $(N=233)$ & Invasive $[N(\%)]$ & $228(97.9 \%)$ & $15(93.8 \%)$ & $83(97.6 \%)$ & $91(97.8 \%)$ & $39(100.0 \%)$ & 0.20 \\
\hline \multicolumn{8}{|l|}{ pT (only invasive tumors) ${ }^{\mathrm{b}}$} \\
\hline \multirow[t]{3}{*}{ Total $(N=700)$} & $\mathrm{T} 1[N(\%)]$ & $503(71.9 \%)$ & $70(81.4 \%)$ & $231(73.6 \%)$ & $153(66.8 \%)$ & $49(69.0 \%)$ & \multirow{3}{*}{$0.02^{\mathrm{c}}$} \\
\hline & $\mathrm{T} 2[N(\%)]$ & $171(24.4 \%)$ & $15(17.4 \%)$ & $74(23.6 \%)$ & $65(28.4 \%)$ & $17(23.9 \%)$ & \\
\hline & $\mathrm{T} 3 \& \mathrm{~T} 4[N(\%)]$ & $26(3.7 \%)$ & $1(91.2 \%)$ & $9(2.9 \%)$ & $11(4.8 \%)$ & $5(7.0 \%)$ & \\
\hline \multirow[t]{3}{*}{ Screen-detected cancer $(N=511)$} & $\mathrm{T} 1[N(\%)]$ & $404(79.1 \%)$ & $63(85.1 \%)$ & $195(79.6 \%)$ & $116(75.8 \%)$ & $30(76.9 \%)$ & \multirow{3}{*}{$0.14^{\mathrm{c}}$} \\
\hline & $\mathrm{T} 2[N(\%)]$ & $97(19.0 \%)$ & $11(14.9 \%)$ & $46(18.8 \%)$ & $33(21.6 \%)$ & $7(17.9 \%)$ & \\
\hline & $\mathrm{T} 3 \& \mathrm{~T} 4[N(\%)]$ & $10(2.0 \%)$ & $0(0.0 \%)$ & $4(1.6 \%)$ & $4(2.6 \%)$ & $2(5.1 \%)$ & \\
\hline \multirow[t]{3}{*}{ Interval cancer $(N=189)$} & $\mathrm{T} 1[N(\%)]$ & $99(52.4 \%)$ & $7(58.3 \%)$ & $36(52.2 \%)$ & $37(48.7 \%)$ & $19(59.4 \%)$ & \multirow{3}{*}{$0.87^{\mathrm{c}}$} \\
\hline & $\mathrm{T} 2[N(\%)]$ & $74(39.2 \%)$ & $4(33.3 \%)$ & $28(40.6 \%)$ & $32(42.1 \%)$ & $10(31.3 \%)$ & \\
\hline & $\mathrm{T} 3$ and $\mathrm{T} 4[N(\%)]$ & $16(8.5 \%)$ & $1(8.3 \%)$ & $5(7.2 \%)$ & $7(9.2 \%)$ & $3(9.4 \%)$ & \\
\hline \multicolumn{8}{|c|}{ Lymph node status (only invasive tumors) ${ }^{\mathrm{d}}$} \\
\hline Total $(N=741)$ & Positive $[N(\%)]$ & $234(31.6 \%)$ & $18(20.2 \%)$ & $105(32.3 \%)$ & $87(35.2 \%)$ & $24(30.0 \%)$ & 0.12 \\
\hline Screen-detected cancer $(N=518)$ & Positive $[N(\%)]$ & $152(29.3 \%)$ & $13(17.6 \%)$ & $75(30.7 \%)$ & $51(32.1 \%)$ & $13(31.7 \%)$ & 0.08 \\
\hline Interval cancer $(N=223)$ & Positive $[N(\%)]$ & $82(36.8 \%)$ & $5(33.3 \%)$ & $30(37.0 \%)$ & $36(40.9 \%)$ & $11(28.2 \%)$ & 0.68 \\
\hline \multicolumn{8}{|l|}{ Tumor diameter (only invasive tumors) $^{\mathrm{e}}$} \\
\hline Total $(N=691)$ & Median (mm) (IQR) & $15(10 ; 22)$ & $12(8 ; 18)$ & $15(10 ; 21)$ & $17(11 ; 25)$ & $14(10 ; 22)$ & 0.01 \\
\hline Screen-detected cancer $(N=500)$ & Median (mm) (IQR) & $13(9 ; 19)$ & $11(8 ; 17)$ & $13(10 ; 19)$ & $14(10 ; 20)$ & $12(8 ; 19)$ & 0.10 \\
\hline Interval cancer $(N=191)$ & Median (mm) (IQR) & $20(14 ; 30)$ & $20(13 ; 33)$ & $19(16 ; 30)$ & $21(16 ; 31)$ & $16(12 ; 25)$ & 0.34 \\
\hline
\end{tabular}

${ }^{a}$ Information on invasiveness is missing for 3 tumors ( 2 screen-detected and 1 interval tumors)

${ }^{\mathrm{b}}$ Information on pT status is missing for 57 tumors (18 screen-detected and 39 interval tumors)

c $p$-trend determined for $\mathrm{T} 1$ versus $\mathrm{T} 2, \mathrm{~T} 3$, and $\mathrm{T} 4$

${ }^{\mathrm{d}}$ Information on lymph node status is missing for 16 tumors (11 screen-detected and 5 interval tumors)

e Information on tumor diameter is missing for 66 tumors (29 screen-detected and 37 interval tumors)

the visual BI-RADS categories and found sensitivities of $82 \%$ in the lowest and $66 \%$ in the highest breast density category [17].

Four other studies where breast density was visually assessed on digital screening mammograms, also found a negative influence of breast density on screening sensitivity $[6-8,22]$ a fifth study did not find this result [23]. A Canadian study showed a lower screening sensitivity for women with $75 \%$ or higher breast density $(74.2 \%$ (95\% CI $67.2-80.4)$ ) compared to women with less than $75 \%$ breast density (80.2\% (95\% CI 78.4-81.9)) when using direct radiography (DR) in a biennial screening program, where women who are considered to be at increased risk were screened annually [8]. In the American Digital Mammographic Imaging Screening Trial (DMIST), the screening sensitivity was determined for women with dense and nondense breasts for several subgroups. Sensitivity seemed higher for all nondense compared to dense subgroup comparisons, with exception of postmenopausal women aged 50-64 years [6]. In a study using data from the Breast
Cancer Surveillance Consortium (BCSC), Kerlikowske et al. found that in an annual screening program, DM screening sensitivity was also significantly lower in the higher BI-RADS breast density categories than in the lower BI-RADS categories for women aged 50-74 years [7]. However, in another paper by Kerlikowske et al., also using BCSC data, no significant differences in screening sensitivity between breast density categories was found, when DM was used [23]. Finally, in a recently published study of Weigel et al., where data of the German biennial screening program was used, screening sensitivity was found to be lower in the higher as compared to the lower breast density categories. In that study, screening sensitivities of 100 and $50 \%$ were found for the lowest and the highest density category, respectively [22].

Although the results in the above studies are not completely consistent, the majority of them showed that screening performance is still negatively influenced by breast density when DM is used instead of FSM. This is also found in the current study. 
Four out of six above-mentioned studies were conducted in the USA [6, 7, 17, 23]. The only European study determining the influence of breast density on digital mammography screening performance was the recently published study of Weigel et al. [22]. However, our study is the first to determine the effect of automatically assessed volumetric mammographic density on DM screening performance in a European population-based screening setting. There are three notable differences between European and American screening programs: (1) recall rates are below $5-7 \%$ in Europe and around $8-10 \%$ in the USA [23-29]; (2) double-reading, which is also used in this study, is common in European screening programs, but not in the USA [30]; (3) the screening interval is different. Biennial screening is common in European countries, while in the USA, women are mostly screened yearly [30].

When looking at the interval cancers diagnosed within the first year after a negative screening mammogram, we found that in the lower density categories, only a small part of the interval cancers were found in the first year after a negative screening examination, and most were found in the second year, whereas in women with extremely dense breasts, this was the other way around. Although a oneyear screening interval instead of a 2-year screening interval would probably result in a higher program sensitivity in all density groups, this will happen to a larger extent in the women with fatty breasts than in those with extremely dense breasts, resulting in larger differences in screening sensitivity across density categories.

When only invasive cancers instead of both invasive and in situ cancers were taken into account, the screening sensitivity decreased most notably in VDG4. This indicates that the detection of invasive breast cancers in DM screening is hampered to a larger extent than the detection of in situ breast cancers (Table 3). A possible explanation for this is that the visibility of microcalcifications, that often are the hallmark of ductal carcinoma in situ (DCIS) on mammography [20], is not hampered as much in dense tissue as the visibility of invasive breast cancers. $89.4 \%$ of the DCIS in our study was accompanied by microcalcifications.

False positive rates were found to be higher in women with dense breasts compared to women with nondense breasts. Similar trends were found in two American studies using BCSC data [7, 31].

When looking at the tumor characteristics of screendetected breast cancers, we observe a significant linear trend for the proportion of invasive tumors over breast density categories ( $p$-trend $=0.03$ ). In addition, the size of screen-detected cancers and the proportion of positive lymph node status among screen-detected cancers seem to be larger in denser breasts. However, no significant linear trend was found for screen-detected tumor size and positive lymph node status proportion across the four density categories $\left(p\right.$-trend $d_{\text {size }}=0.10$ and $p$-trend $d_{\text {lymph node status }}=$ 0.08).

It should be noted that the four density categories (VDGs) used in this study are comparable to the 4th edition BI-RADS density categories. Although in 2013 the $5^{\text {th }}$ BIRADS density edition was introduced, we here still used the VDG categories comparable to the 4th edition, to enable better comparison with previous studies.

A limitation of this study is that during the study period, the MLO view was the standardly acquired view for the subsequent screening rounds and $\mathrm{CC}$ views were only taken in addition to MLO during the first screening round or by indication during subsequent rounds. As a result, breast density was determined based on only MLO views for some examinations and on both MLO and CC views for other examinations in our main analysis. Volpara's PDV measured on $\mathrm{CC}$ views tends to be somewhat higher than on MLO views [32]. As CC views are more often performed among women with dense breasts and women with a suspicious region on their MLO view, breast density might be somewhat artificially elevated for these women. Our sensitivity analysis using VDG categories based on PDV from the MLO views only did not lead to different conclusions. Screening sensitivity is presumably higher when both MLO and CC views are available compared to MLO views only. Therefore, standardly taking both MLO and CC views would lead to higher sensitivity, particularly in women with fatty breasts as they are the ones who most often receive MLO views only. This would lead to larger differences in screening performance across breast density categories.

Strengths of this study are the large sample size and the fact that the digital mammograms were acquired in routine screening. In addition, we used a fully automatic method to determine PDV, which was possible because unprocessed image data were archived. In several studies, this automatic method (Volpara) showed to be correlated with BI-RADS breast density and to give comparable breast cancer risk estimations as with BI-RADS breast density [13, 15, 16]. In addition, it has been validated against MRI [14]. Volpara gives objective and reproducible density measurements, representing the amount of dense tissue rather than the size of the dense tissue projection as measured by area-based methods.

In summary, in a large screening population, where DM was used for screening and a fully automatic method (Volpara) was used to determine PDV, breast density was found to significantly hamper the detection of breast tumors. This is shown by a lower screening sensitivity in women with dense compared to those with nondense breasts, which existed despite a higher recall rate for women with dense breasts. These findings are in line with 
results of most studies using visually assessed BI-RADS density on digital mammograms. Since measuring breast density fully automatically has higher reproducibility than visual assessment, this automatic method could help with facilitating a more tailored screening, such as supplemental screening for women with dense breasts.

Acknowledgements This study has received funding by the European Union's Seventh Framework Programme FP7 (Grant number 306088), and the Dutch Cancer Society (Grant number KWF UU 2009-4348). Diana Miglioretti, PhD (Division of Biostatistics, Department of Public Health Sciences School of Medicine, University of California, Davis, USA), Karla Kerlikowske, MD, PhD (Department of Medicine and Epidemiology/Biostatistics, University of California, San Francisco, USA), and Rebecca Stellato, MSc (Julius Center for Health Sciences and Primary Care, University Medical Center Utrecht, The Netherlands) kindly provided statistical advice for this study. We also want to thank the Foundation of Population Screening Mid-West (The Netherlands) for providing data.

\section{Compliance with ethical standards}

Conflict of interest J. Wanders, K. Holland, R. Mann, P. Peeters, C. van Gils, and N. Karssemeijer report all the same grant from the European Union's Seventh Framework Programme (FP7), during the conduct of the study. N. Karssemeijer also reports to be one of the cofounders of Volpara Solutions, who develops and markets the breast density measurement software Volpara used in this study. In addition, $\mathrm{N}$. Karssemeijer has a patent pending and is co-founder of two other companies in the field of breast imaging next to his position as professor in the University. The two companies are Qview Medical (Los, Altos, CA) and ScreenPoint Medical (Nijmegen, NL). These companies develop products for computer-aided detection of breast cancer, in whole-breast ultrasound and in mammography, respectively. C. van Gils also reports a personal grant from the Dutch Cancer Society, during the conduct of the study and a grant from Bayer Healthcare, and non-financial support from Volpara Solutions outside the submitted work. In addition, R. Mann reports grants, personal fees, and non-financial support from Siemens Healthcare and grants and personal fees from Bayer Healthcare outside the submitted work. R. Mann also reports a research contract with Seno Medical, and he reports to be a scientific advisor for ScreenPoint Medical (Nijmegen, NL) outside the submitted work. W. Veldhuis and R. Pijnappel have nothing to disclose.

Ethical standards The authors declare that this study complies with the current laws in The Netherlands.

Open Access This article is distributed under the terms of the Creative Commons Attribution 4.0 International License (http://crea tivecommons.org/licenses/by/4.0/), which permits unrestricted use, distribution, and reproduction in any medium, provided you give appropriate credit to the original author(s) and the source, provide a link to the Creative Commons license, and indicate if changes were made.

\section{References}

1. McCormack VA, dos Santos Silva I (2006) Breast density and parenchymal patterns as markers of breast cancer risk: a metaanalysis. Cancer Epidemiol Biomark Prev 15(6):1159-1169
2. Vachon CM, van Gils CH, Sellers TA, Ghosh K, Pruthi S, Brandt KR et al (2007) Mammographic density, breast cancer risk and risk prediction. Breast Cancer Res: BCR 9(6):217

3. Boyd NF, Guo H, Martin LJ, Sun L, Stone J, Fishell E et al (2007) Mammographic density and the risk and detection of breast cancer. N Engl J Med 356(3):227-236

4. Kerlikowske K (2007) The mammogram that cried Wolfe. N Engl J Med 356(3):297-300

5. Are You Dense Advocacy Website. [cited 2016 October 29]; Available from: http://www.areyoudenseadvocacy.org

6. Pisano ED, Hendrick RE, Yaffe MJ, Baum JK, Acharyya S, Cormack JB et al (2008) Diagnostic accuracy of digital versus film mammography: exploratory analysis of selected population subgroups in DMIST. Radiology 246(2):376-383

7. Kerlikowske K, Zhu W, Tosteson AN, Sprague BL, Tice JA, Lehman CD et al (2015) Identifying women with dense breasts at high risk for interval cancer: a cohort study. Ann Intern Med 162(10):673-681

8. Prummel MV, Muradali D, Shumak R, Majpruz V, Brown P, Jiang $\mathrm{H}$ et al (2015) Digital compared with screen-film mammography: measures of diagnostic accuracy among women screened in the Ontario breast screening program. Radiology $150-733$

9. Ciatto S, Houssami N, Apruzzese A, Bassetti E, Brancato B, Carozzi $\mathrm{F}$ et al (2005) Categorizing breast mammographic density: intra- and interobserver reproducibility of BI-RADS density categories. Breast 14(4):269-275

10. Gard CC, Aiello Bowles EJ, Miglioretti DL, Taplin SH, Rutter CM (2015) Misclassification of breast imaging reporting and data system (BI-RADS) mammographic density and implications for breast density reporting legislation. Breast J 21(5):481-489

11. Gweon HM, Youk JH, Kim JA, Son EJ (2013) Radiologist assessment of breast density by BI-RADS categories versus fully automated volumetric assessment. AJR Am J Roentgenol 201(3):692-697

12. Redondo A, Comas M, Macia F, Ferrer F, Murta-Nascimento C, Maristany MT et al (2012) Inter- and intraradiologist variability in the BI-RADS assessment and breast density categories for screening mammograms. Br J Radiol 85(1019):1465-1470

13. Brandt KR, Scott CG, Ma L, Mahmoudzadeh AP, Jensen MR, Whaley DH et al (2015) Comparison of clinical and automated breast density measurements: implications for risk prediction and supplemental screening. Radiology 151-261

14. Gubern-Merida A, Kallenberg M, Platel B, Mann RM, Marti R, Karssemeijer N (2014) Volumetric breast density estimation from full-field digital mammograms: a validation study. PLoS ONE 9(1):e85952

15. Seo JM, Ko ES, Han BK, Ko EY, Shin JH, Hahn SY (2013) Automated volumetric breast density estimation: a comparison with visual assessment. Clin Radiol 68(7):690-695

16. Lee HN, Sohn YM, Han KH (2015) Comparison of mammographic density estimation by Volpara software with radiologists' visual assessment: analysis of clinical-radiologic factors affecting discrepancy between them. Acta Radiol 56(9):1061-1068

17. Destounis S, Johnston L, Highnam R, Arieno A, Morgan R, Chan A (2016) Using volumetric breast density to quantify the potential masking risk of mammographic density. AJR. Am J Roentgenol $1-6$

18. Bluekens AM, Karssemeijer N, Beijerinck D, Deurenberg JJ, van Engen RE, Broeders MJ et al (2010) Consequences of digital mammography in population-based breast cancer screening: initial changes and long-term impact on referral rates. Eur Radiol 20(9):2067-2073

19. Karssemeijer N, Bluekens AM, Beijerinck D, Deurenberg JJ, Beekman M, Visser R et al (2009) Breast cancer screening results 
5 years after introduction of digital mammography in a population-based screening program. Radiology 253(2):353-358

20. Bluekens AM, Holland R, Karssemeijer N, Broeders MJ, den Heeten GJ (2012) Comparison of digital screening mammography and screen-film mammography in the early detection of clinically relevant cancers: a multicenter study. Radiology 265(3):707-714

21. Highnam R, Brady M, Yaffe MJ, Karssemeijer N, Harvey J (2010) Robust breast composition measurement-volpara (TM). Lect Notes Comput Sci 6136:342-349

22. Weigel S, Heindel W, Heidrich J, Hense HW, Heidinger O (2016) Digital mammography screening: sensitivity of the programme dependent on breast density. Eur Radiol

23. Kerlikowske K, Hubbard RA, Miglioretti DL, Geller BM, Yankaskas BC, Lehman CD et al (2011) Comparative effectiveness of digital versus film-screen mammography in community practice in the United States: a cohort study. Ann Intern Med 155(8):493-502

24. Pisano ED, Gatsonis C, Hendrick E, Yaffe M, Baum JK, Acharyya $S$ et al (2005) Diagnostic performance of digital versus film mammography for breast-cancer screening. N Engl J Med 353(17): 1773-1783

25. Hambly NM, McNicholas MM, Phelan N, Hargaden GC, O'Doherty A, Flanagan FL (2009) Comparison of digital mammography and screen-film mammography in breast cancer screening: a review in the Irish breast screening program. AJR Am J Roentgenol 193(4):1010-1018
26. van Luijt PA, Fracheboud J, Heijnsdijk EA, den Heeten GJ, de Koning HJ (2013) Nation-wide data on screening performance during the transition to digital mammography: observations in 6 million screens. Eur J Cancer 49(16):3517-3525

27. Henderson LM, Benefield T, Nyante SJ, Marsh MW, GreenwoodHickman MA, Schroeder BF (2015) Performance of digital screening mammography in a population-based cohort of black and white women. Cancer Causes Control: CCC 26(10):1495-1499

28. Kemp Jacobsen K, O’Meara ES, Key D, I Buist, Kerlikowske K, Vejborg Buist et al (2015) Comparing sensitivity and specificity of screening mammography in the United States and Denmark. Int J Cancer. Journal international du cancer 137(9):2198-2207

29. Lee CS, Bhargavan-Chatfield M, Burnside ES, Nagy P, Sickles EA (2016) The national mammography database: preliminary data. AJR Am J Roentgenol 206(4):883-890

30. International Cancer Screening Network (ICSN) website. [cited 2015 November 1]; Available from: http://healthcaredelivery. cancer.gov/icsn/

31. Nelson HD, O’Meara ES, Kerlikowske K, Balch S, Miglioretti D (2016) Factors associated with rates of false-positive and falsenegative results from digital mammography screening: an analysis of registry data. Ann Intern Med

32. Eng A, Gallant Z, Shepherd J, McCormack V, Li J, Dowsett M et al (2014) Digital mammographic density and breast cancer risk: a case-control study of six alternative density assessment methods. Breast Cancer Res: BCR 16(5):439 